June 1995

\title{
Case Report: Sometimes a Cigar is just a Cigar
}

\author{
Zafar Y. Ibrahim, MD \\ University Hospitals of Cleveland \\ Ellen F. Brooks, MD \\ Case Western Reserve University, Cleveland, Ohio
}

Follow this and additional works at: https://jdc.jefferson.edu/jeffjpsychiatry

Part of the Psychiatry Commons

Let us know how access to this document benefits you

\section{Recommended Citation}

Ibrahim, MD, Zafar Y. and Brooks, MD, Ellen F. (1995) "Case Report: Sometimes a Cigar is just a Cigar," Jefferson Journal of Psychiatry. Vol. 12 : Iss. 2 , Article 3.

DOI: https://doi.org/10.29046/JJP.012.2.010

Available at: https://jdc.jefferson.edu/jeffjpsychiatry/vol12/iss2/3

This Article is brought to you for free and open access by the Jefferson Digital Commons. The Jefferson Digital Commons is a service of Thomas Jefferson University's Center for Teaching and Learning (CTL). The Commons is a showcase for Jefferson books and journals, peer-reviewed scholarly publications, unique historical collections from the University archives, and teaching tools. The Jefferson Digital Commons allows researchers and interested readers anywhere in the world to learn about and keep up to date with Jefferson scholarship. This article has been accepted for inclusion in Jefferson Journal of Psychiatry by an authorized administrator of the Jefferson Digital Commons. For more information, please contact: JeffersonDigitalCommons@jefferson.edu. 


\title{
Case Report: Sometimes a Cigar Is Just a Cigar
}

\author{
Zafar Y. Ibrahim, M.D. \\ Ellen F. Brooks, M.D.
}

\begin{abstract}
This unusual case underscores the need for psychiatrists to consider treatable and curable causes of acute behavior changes even when historical data are not easily available. This case presentation invites physicians of mind (and body) to utilize simple and common-sense approaches while evaluating their patients.
\end{abstract}

\section{CASE REPORT}

A 40-year-old single Caucasian man was admitted to the hospital because of relapse of psychosis and suicidal ideation. The patient had stopped taking his lithium and haloperidol several days prior and was experiencing auditory hallucinations. $\mathrm{He}$ claimed that voices were telling him to throw himself in front of a car. The patient had a stressful relationship with his father and sister because they had not allowed him to stay with them. The patient was unemployed and homeless.

His psychiatric history included multiple admissions for schizoaffective disorder, polysubstance abuse (alcohol, marijuana, cocaine), and antisocial personality disorder. There was a history of a suicide attempt in 1974 by hanging. His outpatient medications included lithium, benztropine, and haloperidol. The patient was noncompliant regarding outpatient medications as evidenced by subtherapeutic serum levels at the time of his admission to the hospital. He smoked three packs of cigarettes per day and was currently abusing marijuana. There was no history of medical or surgical illness.

\section{Mental Status Examination}

The patient was alert, oriented, and well groomed. His behavior was appropriate for the interview. His mood was depressed; he displayed constricted affect and mild agitation. Thought content included suicidal ideation and auditory command hallucinations, as mentioned previously. He scored 29/30 on the Mini Mental State Examination (1) with a deficit in delayed recall. His judgement was noted to be poor, as was insight into his diagnosis and his social and environmental situation.

Zafar Y. Ibrahim, M.D. is a PGY-3 resident in the Department of Psychiatry at the Veterans Affairs Medical Center and the University Hospitals of Cleveland. Ellen F. Brooks, M.D. is an Assistant Professor of Psychiatry at Case Western Reserve University. 


\section{Medical Examination}

Physical examination at the time of admission revealed a well-developed, Caucasian man. He appeared to be in no physical distress and he denied any current medical problems. The results of his physical examination were within normal limits.

Laboratory findings at the time of admission were unremarkable except for a urine toxicology screen positive for marijuana, a white blood cell count of $12.3 \times$ $10^{9} / \mathrm{L}$, and a serum lithium level of 0.1 . Because the patient was afebrile and did not complain of any physical problems, his mildly increased white blood cell count was attributed to stress.

\section{Impression}

The admitting diagnoses were schizoaffective disorder in acute exacerbation and cannabis abuse. He was assessed to be a moderate suicide risk as an outpatient because of his past suicide attempt in 1974, presence of auditory hallucinations, and poor judgement.

\section{Clinical Course}

During his hospitalization, the patient received lorazepam, haloperidol, lithium, benztropine mesylate, and diphenhydramine hydrochloride. This treatment regimen resulted in a decrease in his psychosis and agitation. By the sixth hospital day the patient's auditory hallucinations had significantly decreased. On day 12 of his hospital stay, he complained of right-sided headache and was given acetaminophen and ibuprofen; these were ineffective in controlling his pain.

The patient was observed, on day 13, to be standing in a hallway holding his throat as if trying to choke himself. When asked if something was wrong, he abruptly stopped this gagging behavior and calmly requested "syrup of Ipecac," saying that he wanted to vomit. When asked why he wanted to vomit, he denied that anything was wrong, and repeated his request for syrup of Ipecac. The patient was told that he would not be given such medicine if he had no medical reason for it. He later claimed he could not hear, although he was able to communicate with staff, and that his teeth hurt. The on-call resident evaluated the patient, noted that his ear was tender during the exam, and believed that a cerumen plug was the cause of the hearing difficulty.

On further questioning as to a possible cause for the ear tenderness, the patient recalled using a nail to clean his ears. He stated, "I think the nail got broken because I saw only half the nail in my hand, so maybe the other half is still in my ear." The patient denied having any discharge from his right ear.

The patient was taken to the radiology department where plain roentgenograms of his skull (Figure) revealed a round, button-sized foreign body deep in his external auditory canal. The patient was given a local anesthetic and the foreign body was removed by an ear, nose, and throat specialist using an operative microscope. The foreign body proved to be a button-sized alkaline battery. At this point the patient 


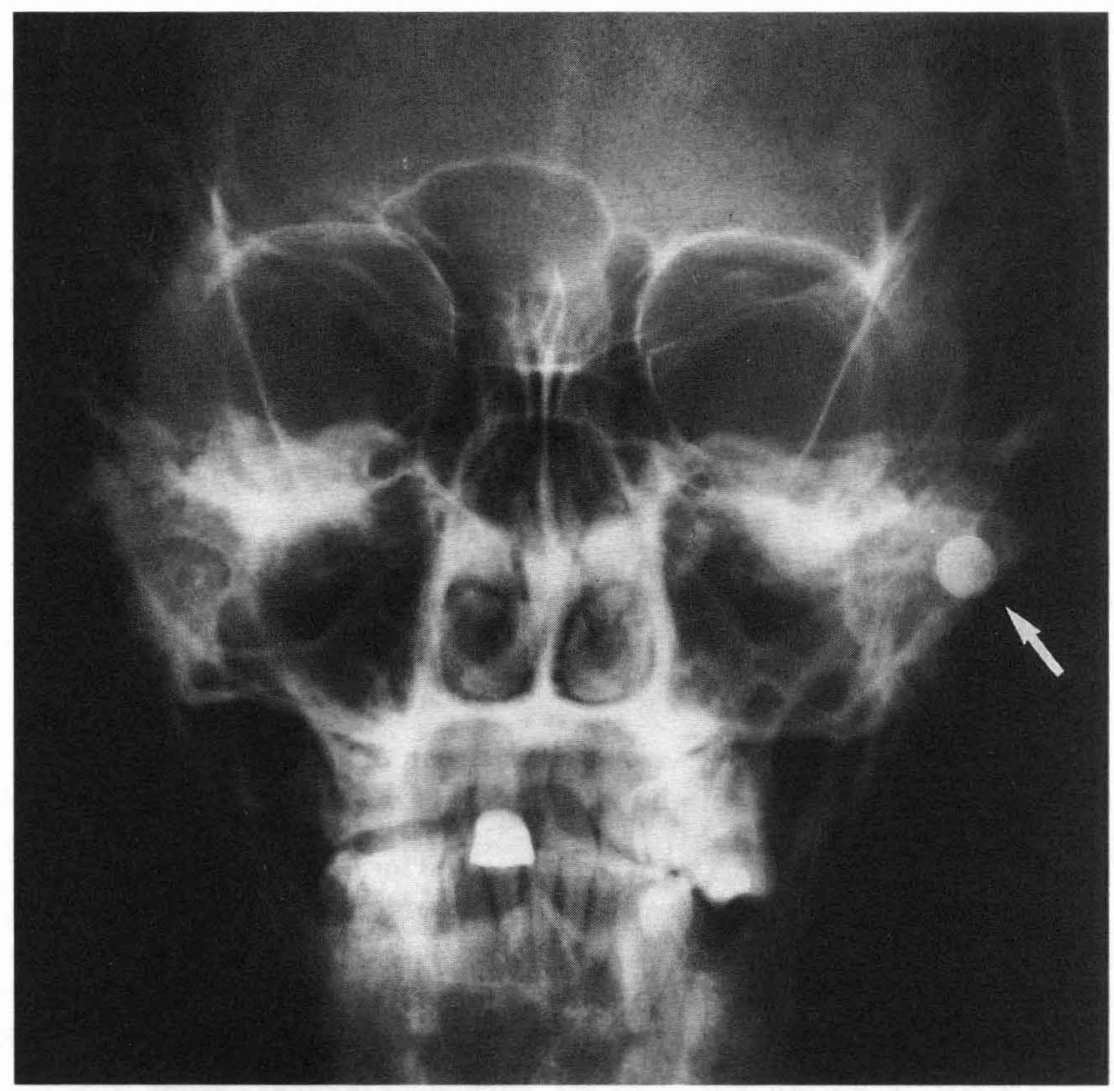

Figure. Posteroanterior roentgenogram of patient's skull shows alkaline battery deep within the right auditory canal.

told us, "Now I remember that before coming to the hospital I was listening to music using an earphone, and I think that is how this battery got transferred into my ear."

After the battery was removed the patient's pain disappeared during the next 24 to 48 hours. His hearing improved, and his desire to vomit resolved.

\section{DISCUSSION}

There are several striking aspects to this case. First, this odd behavior (choking oneself) might be easily dismissed in a suicidal, psychotic patient as simply manifestations of the underlying psychiatric disease. Second, this patient did not initially complain of pain in his ear, although a relatively large foreign body was lodged deep within the external auditory canal, and during removal of this foreign body the patient experienced significant pain. Third, the foreign body was not visible in the auditory canal and required radiological evaluation for detection. Fourth, the patient 
seemed unable or unwilling to tell the physicians that there was something in his ear, although he had almost certainly placed it there himself. These details made the correct diagnosis of a foreign body in the ear potentially very easy to miss.

Acutely psychotic patients may be unable to verbalize the presence of physical problems due to limitations in communication caused by their psychosis. In this case, the battery was lodged very deep within the auditory canal and could have been irritating nerves responsible for eliciting a gagging sensation. Alternatively, the patient could have been trying to expel something he knew was there but was not able to consciously or verbally acknowledge (he insisted on trying to vomit it out instead of requesting manual removal).

Psychotic patients have been known to self-mutilate or stuff their body cavities. Patients give varied explanations for such acts-religious reasons (2), auditory command hallucinations, and to assuage feeling of emptiness or to fill a psychic void (3). In 1989, Favazza et al concluded "deviant self-mutilation is best thought of as a purposeful, if morbid, act of self-help" (2). Interestingly, although there are several psychosis-related causes for ear stuffing, in some cases, patients may benefit from the restriction of auditory input. The use of earplugs has been associated with a reduction in auditory hallucinations in a subgroup of patients with chronic psychoses (4).

A routine physical examination and laboratory analysis, as was initially done in this case, may not uncover the real cause of the physical problems. Although the mildly elevated white blood cell count was originally thought to be caused by stress, in retrospect it may have been due to an inflammatory process in this patient's right ear. In this case, we were able to elicit extreme tenderness on manipulation of the patient's right ear, leading us to suspect an organic problem even when there was no visible abnormality. Fortunately the patient was immediately reexamined; the lodging of an alkaline battery in the external auditory canal constitutes a true emergency, as leaking alkali can cause liquefaction necrosis of skin, bone, and the tympanic membrane, as well as facial nerve palsy (5).

The importance of obtaining a roentgenogram to evaluate this patient's complaint is obvious, and serves as a vivid reminder that, to paraphrase a remark commonly attributed to Freud, sometimes a cigar is just a cigar, and even apparently delusional complaints may need further evaluation.

\section{REFERENCES}

1. Folstein MF, Folstein SE, McHugh PR: Mini-Mental State: a practical method for grading the cognitive state of patients for the clinician. J Psychiatr Res 1975; 12:189-198

2. Favazza AR. Why patients mutilate themselves. Hosp Community Psychiatry 1989; 40:137145

3. Kroll TC, Wise TN. Cited by: Weiser M, Levy A, Neuman M, et al: Ear stuffing: An unusual form of self-mutilation. J Nerv Ment Dis 1993; 181:587-588

4. Birchwood M: Control of auditory hallucinations through occlusion of monaural auditory input. BrJ Psychiatry 1986; 149:104-107

5. McRae M, Premachandra DJ, Gatland J: Button batteries in the ear, nose, and cervical esophagus: A destructive foreign body. J Otolaryngol 1989; 16(6):317 